\title{
Colonic Diverticular Disease: Current Perspectives
}

\author{
Tappenden J, Shrestha BM \\ Department of General Surgery, Northern General Hospital, Sheffield, UK
}

\begin{abstract}
Diverticular disease is a common condition affecting large intestine in the western world, which, although remains asymptomatic in majority of people, can present with abdominal pain, acute diverticulitis, perforation, haemorrhage, intestinal obstruction and fistulation through neighbouring organs. Complicated colonic diverticular disease (CDD) is associated with significant morbidity and mortality. Increasing urbanisation globally with intake of diet deficient in fibres has led to CDD as a significant problem; hence awareness of CDD is paramount for its prevention and appropriate management. The purpose of this article is to provide a comprehensive review of the epidemiology, pathophysiology, clinical presentations, and current management of diverticular disease of the colon and its complications.
\end{abstract}

Key words: Colon, Complications, Diverticulosis, Management

\section{INTRODUCTION}

Colonic diverticular disease (CDD) is an acquired condition marked by mucosal herniation through defects in the colonic wall, termed both as a "disease of the 20th century" and a "disease of Western civilization", although remains asymptomatic in majority of cases, should be entertained in the differential diagnosis of all patients presenting with abdominal pain. ${ }^{1}$ Complications of CDD, however, can cause significant morbidity and mortality, leading to a significant financial impact on health care systems. The management of the CDD through a multidisciplinary team consisting of surgeons, physicians, radiologists, dieticians and stoma therapists leads to best outcomes. $^{2}$ This article provides an up to date review on the aetiopathogenesis and management of CDD with special emphasis on the controversies surrounding the management of its complications.

\section{EPIDEMIOLOGY}

The prevalence of CDD is difficult to measure, as most patients remain asymptomatic. Although CDD is rare under the age of 40 its prevalence is known to increase with age. Post-mortem studies estimate the prevalence to be approximately $5-10 \%$ of people up to 50 years of age, $30 \%$ of those $>50$ years of age, $50 \%$ of those $>70$ years of age, and $66 \%$ of people $>85$ years of age. ${ }^{3}$ It is estimated that $10-20 \%$ of those with CDD will become symptomatic, $1-2 \%$ will require hospitalisation and $0.5 \%$ will require surgery. There is no gender variation. ${ }^{4}$

There is marked geographical variability in prevalence of CDD, being rare in Africa and Asia, but extremely common in USA, Europe and Australasia. To the authors' knowledge, there is no reported cases of CDD from

\author{
Correspondence: \\ Mr. B. M. Shrestha \\ Department of General Surgery \\ Northern General Hospital, \\ Sheffield S5 7AU, UK \\ Email: shresthabm@doctors.net.uk
}


Tappenden et al. Colonic Diverticular Disease: Current Perspectives

Nepal, although one of the authors (BMS) had treated two cases of CDD personally in the past. Progressive urbanisation within a country can lead to increased prevalence, which is thought to be related to changes in dietary intake and Nepal could not be an exemption. ${ }^{5}$ Lack of its awareness is the main reason for missed diagnosis. It is also noted that there is a difference in the colonic location of diverticulae between the Asian and Western population. In Europe and the US, $90 \%$ of people with diverticulosis have sigmoid involvement, and only $15 \%$ have right-sided involvement. Oriental and Asian communities have largely caecal and rightsided diverticulosis. ${ }^{6}$

\section{AETIOLOGY}

Burkitt and Painter hypothesised that deficiency of fibre in the diet, altered collagen structure related to advancing age and disordered colonic motility are the factors which predispose to CDD. ${ }^{7}$ The bowel transit time was significantly affected by the bulk and fibre content. In a study comparing 1200 UK and Ugandan people, which found that the UK cohort had a bowel transit time of 80 hours and mean stool weight of $110 \mathrm{~g} /$ day, compared with the Ugandan cohort which had a transit time of 34 hours and mean stool weight of $450 \mathrm{~g} / \mathrm{day} .{ }^{8}$

These lead to increased intra-luminal pressures and colonic segmentation, thus predisposing to herniation and promoting diverticulae formation in accordance with Laplace's law. ${ }^{9}$ Mimura et al. demonstrated that diverticulosis is associated with altered collagen content and tissue inhibitor of metalloproteinases expression. These factors may participate in the remodelling of gut wall and formation of diverticulae as is seen in patients with Ehler-Danlos and Marfan's syndrome have been noted to develop CDD disease at an early age. ${ }^{10,11}$ Animal and human studies have shown increased intracolonic pressures in CDD. ${ }^{12}$ In symptomatic uncomplicated CDD patients, 24-hour manometry demonstrates significantly increased daily motor activity, except in the transverse colon, not commonly site of CDD, and propulsive activity. ${ }^{13}$

\section{PATHOLOGY}

Colonic diverticulae are pulsion diverticulae (pseudodiverticulae) as they lack normal smooth muscle layers and consist predominantly of mucosa, which occur at the weakest points of the colonic muscle wall, penetrating through the muscularis propria adjacent to the taenia coli, at the site of penetration of the vasa recta. Typical diverticulae are $5-10 \mathrm{~mm}$ in diameter. ${ }^{14}$
Cardinal features of the sigmoid colon in CDD are abnormalities of the muscularis propria, including thickening and elastosis of the taeniae, shortening of the bowel, and thickening and folding of the circular muscle with the development of transverse semilunar ridges between the mesenteric and antimesenteric taeniae. ${ }^{15}$ They usually are asymptomatic, but can present with the diverticulitis, perforation or obstruction. ${ }^{16}$

\section{PRESENTATIONS}

Although majority of patients with CDD are asymptomatic and remain undiagnosed, $25 \%$ of them develop symptoms, sometimes overlapping with irritable bowel syndrome, but $10-25 \%$ will suffer from diverticulitis and $3-5 \%$ with diverticular bleeding. ${ }^{17}$ They present in one of the three ways: (1) as an emergency with acute diverticulitis or complications; (2) electively with lower abdominal pain, and (3) following investigations to exclude other pathologies, usually colonic malignancy. The diversity of presentations of CDD is highlighted in Table-1.

\section{DIAGNOSTIC IMAGINGS}

Barium enema (Figure 1) has traditionally been the most commonly performed investigation, which is gradually

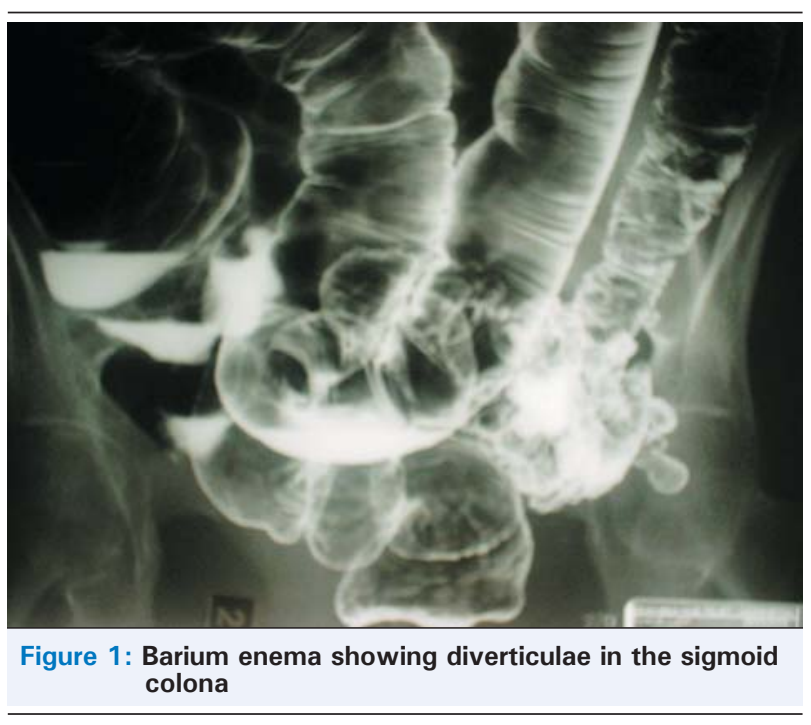

being replaced by computerised scan (CT). ${ }^{17}$ CT scan of the abdomen and pelvis with IV, oral and sometimes rectal contrast has sensitivities of $93-98 \%$ for demonstrating CDD, with specificity of $75-100 \%$, and has been shown to be significantly more accurate than barium enema. ${ }^{18}$ In addition, it is the imaging technique of choice in depicting complications such as acute 
Tappenden et al. Colonic Diverticular Disease: Current Perspectives

\begin{tabular}{|lll|}
\hline Table 1. Presentations of chronic diverticular disease & \\
\hline SPECTRUM OF DISEASE & PRESENTATIONS \\
DIVERTICULOSIS & Presence of diverticular disease \\
& May remain entirely asymptomatic & \\
PAINFUL DIVERTICULAR DISEASE & Colicky abdominal pain, exacerbated by diet \\
& No evidence of inflammation & \\
DIVERTICULITIS & Considerable overlap with functional bowel disease \\
COMPLICATED DIVERTICULAR DISEASE & Inflammation of diverticulae, which may progress to complicated \\
diverticular disease & Perforation & Leading to peritonitis \\
& Abscess formation & Pelvic \\
& & Intra-peritoneal, but distant \\
& Fistulae formation & Colovaginal \\
& & Colovesical \\
& & Colocutaneous \\
\end{tabular}

diverticulitis (Figure 2), perforation, abscess and fistulae formation (Figure 3). ${ }^{19}$ However, the initial imaging modality may vary due the local availability and expertise. $A$ recent UK based survey demonstrated that $\mathrm{CT}$ scan with IV and oral contrast is the most commonly used modality for initial investigation (42\%). Forty percent use barium enema and 31 percent use a combination of barium enema and sigmoidoscopy as follow-up investigations. ${ }^{20} \mathrm{~A}$ significant proportion of patients with CDD undergo to colonoscopy exclude an underlying malignancy. ${ }^{21}$

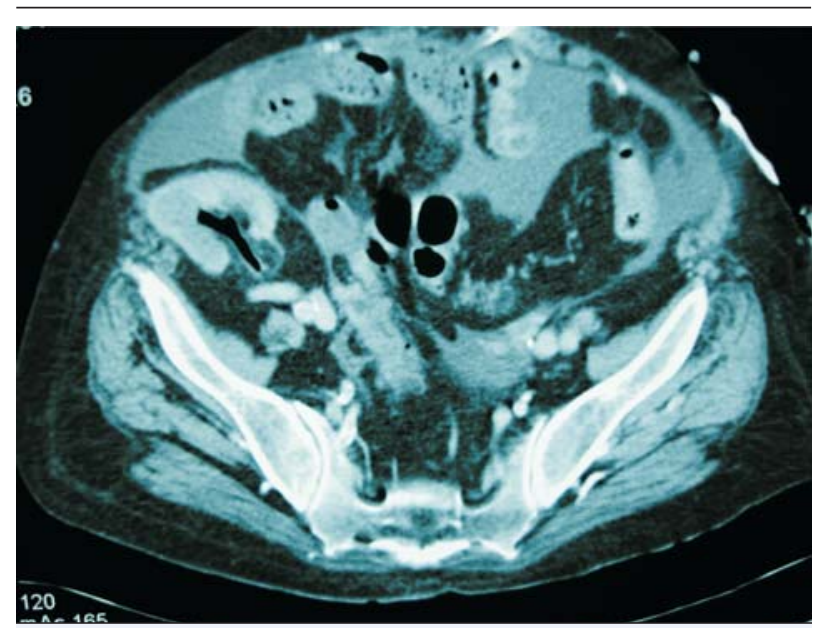

Figure 2. CT scan showing acute diverticulitis

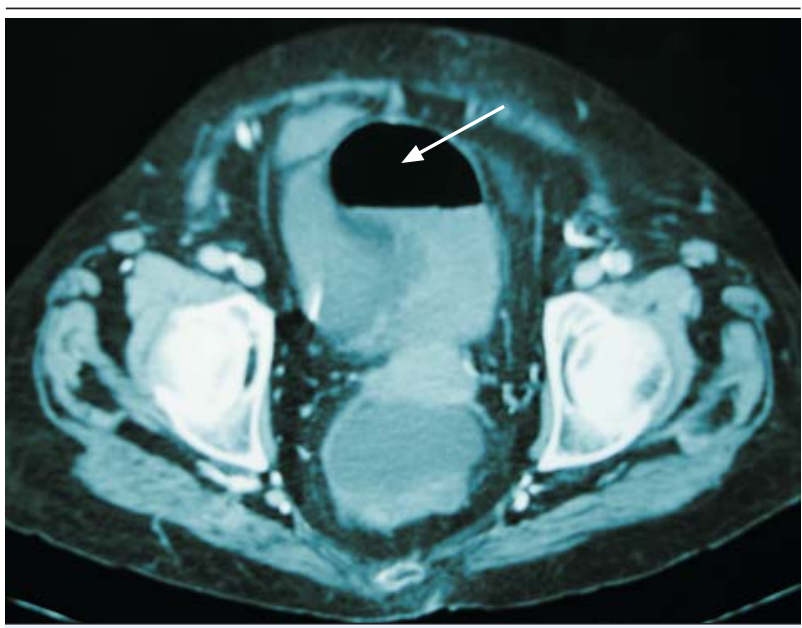

Figure 3. CT scan showing gas in the urinary bladder indicating colovesical fistula

\section{MANAGEMENT}

1. Uncomplicated colonic diverticular disease

As CDD is a complex syndrome that includes several clinical conditions, each needs different therapeutic strategies. In patients with asymptomatic CDD, a fibrerich diet should be recommended in an attempt to reduce intra-luminal pressure and reduce the progression of the disease. ${ }^{22}$ Fibre supplementation is also indicated in symptomatic CDD in order to attain symptom relief and prevent acute diverticulitis. A large prospective study in the United States consisting of 51,529 male health professionals followed up for 4 years demonstrated the 
benefit of prophylactic high fibre diet. During the study only 385 new cases of symptomatic diverticular disease were diagnosed and there was an inverse association with a high fibre diet. ${ }^{23}$

There is some trial data emerging to suggest treatment with high fibre diet and rifaximin, a poorly absorbed antibiotic, for seven days every month reduces symptom frequency and lowers the complication rate in uncomplicated CDD. However, this has not been added to our current management strategy in this region. ${ }^{24}$ Both mesalazine and probiotic like Lactobacillus casei seem to be effective in preventing recurrence of symptomatic uncomplicated CDD. ${ }^{25}$ These preventive strategies are aimed at improving patients' quality of life, preventing complications and thus reducing management costs.

\section{Acute diverticulitis}

Acute diverticulitis is the most common presentation of CDD affecting $10-25 \%$ of patients, and is becoming an increasingly common cause for hospital admission in western society. ${ }^{26}$ The commonest clinical presentation is of left lower quadrant pain with mild diarrhoea, pyrexia leucocytosis and raised inflammatory markers. The patient present with features of localised or generalised peritonitis depending upon the size of the perforation and degree of contamination. Those patients with a long redundant loop of sigmoid colon may present with supra-pubic or right iliac fossa pain. A CT scan of the abdomen and pelvis has been shown to be the best modality for confirming the diagnosis and is extremely beneficial in guiding further clinical management, particularly if complications of diverticulitis are suspected. ${ }^{27}$

Patients with mild symptoms and minimal systemic disturbance can be managed in a primary care setting with antibiotics and light diet, but many will require admission to hospital. Hospitalization, bowel rest, and intravenous antibiotics are mandatory for those with complicated diverticulitis. On admission, initial work-up includes routine blood tests, plain abdominal and erect chest $\mathrm{x}$-rays to exclude a pneumo-peritoneum. ${ }^{28} \mathrm{~A}$ recent survey in the UK showed that ninety-four percent used an antibiotic combination of second or third generation cephalosporin and metronidazole, and bowel rest. ${ }^{29}$ If conservative management fails, further imaging is indicated to assess for complications or an alternative diagnosis. It is an established practice to perform colonoscopy once the acute episode has resolved to exclude an underlying malignancy if there is any diagnostic uncertainty. Colonoscopy is avoided in the acute setting due to the increased risk of colonic perforation. ${ }^{30}$
$15-30 \%$ of those admitted with acute diverticulitis will fail to settle with conservative management and require surgery during their first admission. Recurrent attacks of diverticulitis are common in up to $45 \%$ of patients. ${ }^{31}$ which are less likely to respond to conservative treatment and increased risk of developing complications. ${ }^{32}$ This has led most centres to advocate elective resection after two attacks of uncomplicated diverticulitis. ${ }^{33}$ However, a recent UK based study canvassed the current management practices of colorectal surgeons in the East Anglia region. In patients older than aged 50 years, elective resection would be considered by a majority ( 51 percent) only when complications arose. In those aged 50 years or younger, 35 percent would resect only if complications arose, and only 6 percent would perform resection after a single episode of acute diverticulitis. ${ }^{20}$

\section{Perforated diverticular disease}

The clinical manifestations of perforated diverticular disease (PDD) are dependent on the degree of extracolonic contamination and the ability of the body to contain the infection. PDD is a cause of significant morbidity and mortality, where the mortality rate of 12 $36 \%$ reported in different series have remained unchanged over the last two decades despite improvements in antibiotic therapy, critical care management and surgical techniques. ${ }^{34,35}$ The PDD leads to purulent peritonitis initially, which may progress rapidly to faecal peritonitis if the initial perforation is large. This forms the basis of the Hinchey classification of PDD (Table 2). ${ }^{36}$

\begin{tabular}{|ll|}
\hline Table 2. Hinchey classification \\
\hline Stage I & Diverticulitis with pericolic abscess \\
Stage II & $\begin{array}{l}\text { Diverticulitis with pelvic abscess or } \\
\text { localised abscess }\end{array}$ \\
Stage III & Diverticulitis with purulent peritonitis \\
Stage IV & Diverticulitis with faecal peritonitis
\end{tabular}

CT scan is the best modality stage the PDD. Patients with small pericolic abscesses (Hinchey-I and some II) can be managed conservatively with antibiotics and bowel rest. CT-guided drainage of localised abscesses is an invaluable management option and can enable patients to undergo single stage procedure with primary anastomosis, avoiding a two stage procedure with an interval colostomy. ${ }^{27}$ However not all abscesses are amenable to percutaneous drainage, therefore surgical drainage and resection will need to be considered. ${ }^{37}$ 
Depending on the degree of contamination and patient factors such as co-morbidities, albumin, and the level of inotropic support, a single stage procedure with primary anastomosis or a two stage procedure with interval colostomy is performed. ${ }^{38}$ Primary colectomy with immediate or delayed anastomosis is the best surgical procedure for complicated CDD in patients with good biologic status. Two-stage operations such as colostomy and drainage coupled with late colectomy remain the viable alternative in patients with complicated CDD and critical biologic condition. As advanced age, comorbid conditions, and perioperative sepsis predict mortality, it is suggested that further reduction in mortality will require improvement in medical management of perioperative sepsis and co-morbid conditions. ${ }^{39}$

Patients must be made aware during the consent process that if a colostomy is deemed necessary at laparotomy, less than $50 \%$ of patients will subsequently undergo restoration of intestinal continuity. ${ }^{40}$ Although a recent study of 63 patients who underwent a Hartmann's procedure for complicated diverticular disease, $96.9 \%$ of patients had their bowel continuity restored with a morbidity of $38.5 \%$ and a mortality of $3.1 \%$, suggesting a in high percentage of patients the Hartmann procedure could be restored with a low mortality. 41

\section{Haemorrhage}

Bleeding from a CDD is common and accounts for $40 \%$ of cases of lower GI haemorrhage. ${ }^{4}$ It is estimated that $3-5 \%$ of patients with diverticulosis will have an episode of severe haemorrhage. ${ }^{42}$ Patients present with painless and profuse fresh rectal bleeding, but rarely exsanguinating. It may be associated with mild left lower quadrant cramps and the urge to defaecate. In 70-80\% of patients the haemorrhage ceases spontaneously, with a re-bleeding rate of $22-38 \% .{ }^{43}$

Initial patient management involves resuscitation followed by an upper gastrointestinal (GI) tract endoscopy to exclude a major upper GI bleed and proctoscopy to exclude a anorectal cause such as haemorrhoids. ${ }^{44}$ If bleeding continues, mesenteric angiography is carried out to identify the site of bleeding which should be followed by a limited hemicolectomy if an actively bleeding source is identified (Figure 4, a-c). ${ }^{45}$ Contrast enhanced CT scan is being increasingly used to localise the source of bleeding. ${ }^{46}$ Depending on the local expertise, embolisation of the bleeding point may be attempted, which has been shown to be safe and effective. ${ }^{47}$ On table colonoscopy for the diagnosis and localisation of a bleeding point is often unsuccessful in the presence

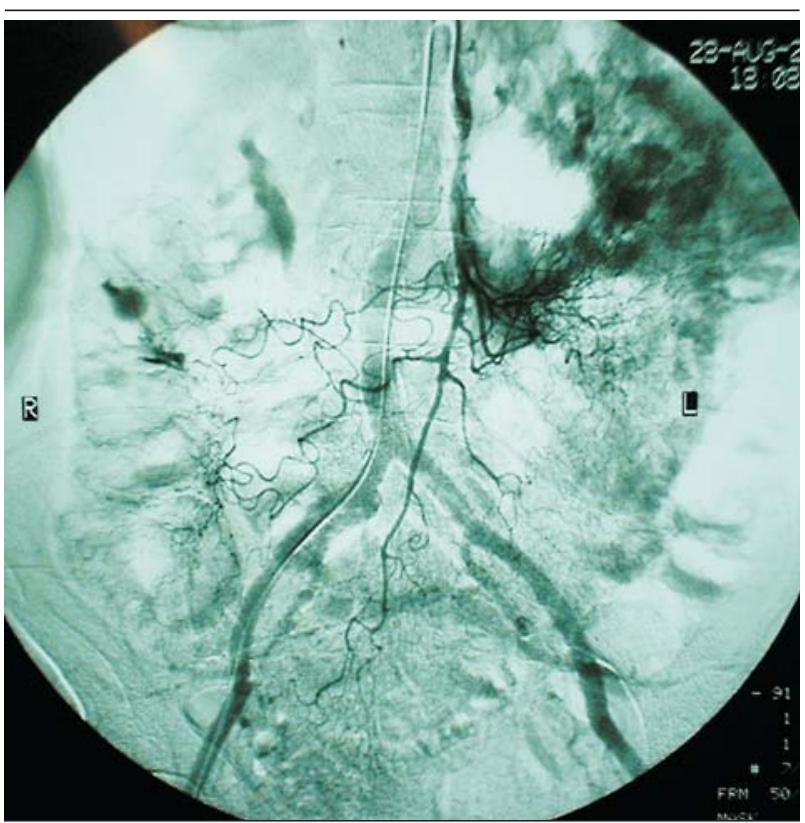

Figure 4. (a) Mesenteric angiogram showing extravasation of contrast within a bleeding caecal diverticulum (arrowed).

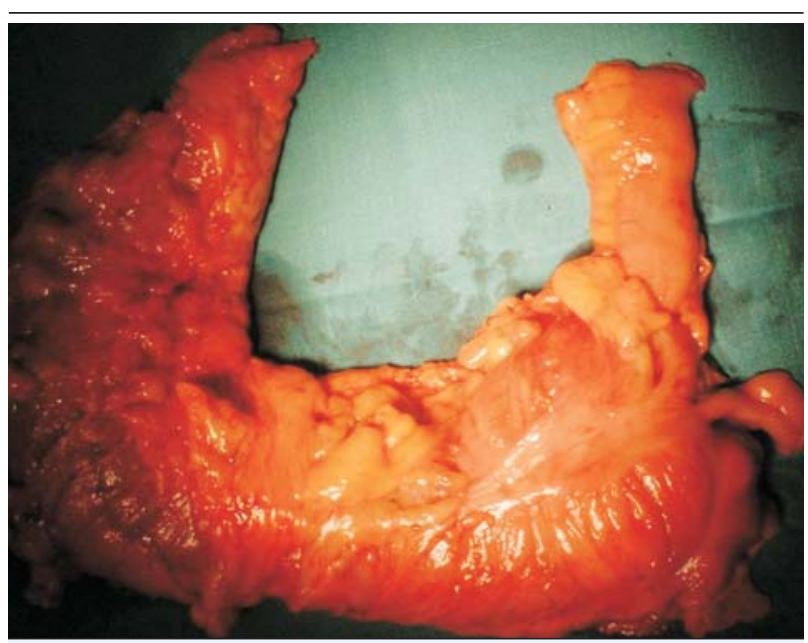

Figure 4. (b) limited right hemicolectomy specimen

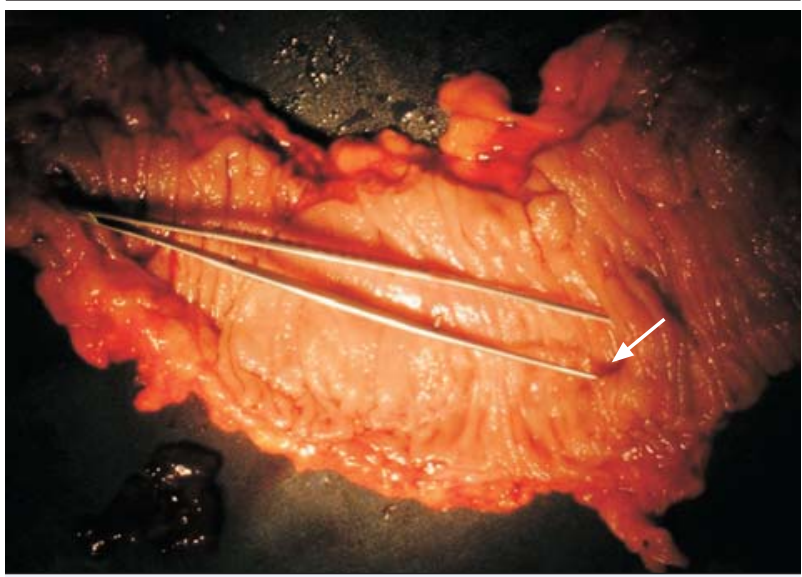

Figure 4. (c) opened up specimen with bleeding site (arrowed). 
Tappenden et al. Colonic Diverticular Disease: Current Perspectives

of active bleeding. ${ }^{48}$ If angiography is not available, and the site of bleeding unknown, a subtotal colectomy is an option, which, at times, may not prove successful. If the bleeding settles with conservative management, a colonoscopy should be performed as an out-patient to exclude a colonic neoplasm. ${ }^{30}$

\section{Fistulae}

a. Colovesical fistula

Colovesical fistula (CVF) is the most common type (65\%) of fistula associated with CDD which results from erosion of the bladder by an inflammatory phlegmon. There is a 2:1 male to female preponderance, as the bladder is protected by the uterus in the female. Pneumaturia and faecaluria in association with a recurrent urine infection are the presenting features. ${ }^{49}$ Diagnosis is confirmed by CT scan which may show presence of gas the bladder (Fig ). A CT with rectal contrast may show the fistula. A cystoscopy and flexible sigmoidoscopy should be performed to exclude malignancy. A one-stage primary resection of sigmoid colon with colorectal anastomosis together with disconnection of the CVF followed by simple closure, reinforcement with an omental flap, or resection and closure of bladder defect is possible in $90 \%$ of the patients. ${ }^{50}$

\section{b. Colovaginal fistula}

Colovaginal fistulae account for a further $25 \%$ of fistula cases which occurs in females who have previously had a hysterectomy. ${ }^{51}$ The passage of flatus or stool per vagina is pathognomonic features. Treatment should consist of similar pathway as with colo-vesical fistula, that is, primary resection and repair of the fistula. ${ }^{52}$ If patients are not deemed fit enough to tolerate resection, a defunctioning colostomy for symptomatic relief may be adequate.

\section{c. Other fistulae}

Colo-enteric, colo-cutaneous, colo-uterine, colo-salpingeal and colo-urethral are less common, which are managed like other fistulae described earlier on. ${ }^{53-55}$

\section{Intestinal Obstruction}

Patients with CDD may present with feature of intestinal obstruction secondary to the relative luminal narrowing from inflammation, or from an extrinsic compression by pericolic abscess. Recurrent diverticulitis can lead to progressive fibrosis and stricture formation. ${ }^{56} \mathrm{~A}$ contrast enema or a CT scan will confirm the diagnosis and excludes a pseudo-obstruction. A high grade stricture or complete obstruction requires limited resection. For a stricture detected on barium enema, a colonoscopy and biopsy should be undertaken to exclude malignancy. If neoplasia can not be excluded, an en bloc (cancer style) resection should be performed. Colonic stenting for diverticular strictures have been conducted but with less favourable outcomes than that for tumour. ${ }^{57}$

\section{LAPAROSCOPIC COLECTOMY}

Laparoscopic management of sigmoid diverticular disease has emerged as an important adjunct to the existing armamentarium which offers earlier restoration of intestinal function and resumption of normal diet, less postoperative pain and lower morbidity, thus facilitating earlier discharge from hospital and quicker return to normal daily activities. ${ }^{58}$ Although there are no prospective randomized studies directly comparing laparoscopic (LC) and open colectomy (OC) for diverticulitis, comparative studies provide compelling data. A French study has demonstrated LC offered significantly lower morbidity than OC $(31.4 \%$ vs. $16.0 \%, p<0.001)$, leading to reduced hospital stay ( 18 days vs. 10 days, $\mathrm{p}<0.001$ ). ${ }^{59}$ The magnitude of benefits achieved with LC in the hands of experienced laparoscopic colorectal surgeons may soon be sufficient to make LC as a routine procedure. ${ }^{60}$

\section{CONCLUSIONS}

CDD is a common disease in the western and affluent society carrying a significant morbidity and mortality. With the increasing urbanisation in the developing world such as Nepal, the emergence of cases of CDD must be borne in mind while dealing with patients with abdominal pain. Missed diagnosis of CDD can lead to inappropriate management, including unnecessary surgical intervention. Measures to prevent its development and subsequent progression to complications should be adopted through a multidisciplinary approach. An aggressive treatment in the form of primary resection of the diseased bowel should be carried out whenever indicated, which would reduce the mortality and improve the long-term outcomes.

\section{REFERENCES}

1. Tursi A. Diverticular disease of the colon. Lancet 2004; 363(9418):1397-8.

2. Frieri G, Pimpo MT, Scarpignato C. Management of colonic diverticular disease. Digestion 2006; 73 Suppl 1:58-66.

3. Tursi A. New physiopathological and therapeutic approaches to diverticular disease of the colon. Expert Opin Pharmacother 2007; 8(3):299-307.

4. Stollman N, Raskin JB. Diverticular disease of the colon. Lancet 
2004; 363(9409):631-9.

5. Chia JG, Wilde CC, Ngoi SS, et al. Trends of diverticular disease of the large bowel in a newly developed country. Dis Colon Rectum 1991; 34(6):498-501.

6. Almy TP, Howell DA. Medical progress. Diverticular disease of the colon. N Engl J Med 1980; 302(6):324-31.

7. Painter NS, Burkitt DP. Diverticular disease of the colon: a deficiency disease of Western civilization. Br Med J 1971; 2(5759):450-4.

8. Gear JS, Brodribb AJ, Ware A, Mann JI. Fibre and bowel transit times. Br J Nutr 1981; 45(1):77-82.

9. Painter NS. Pressures in the colon related to diverticular disease. Proc R Soc Med 1970; 63 Suppl:144-5.

10. Mimura T, Bateman AC, Lee RL, et al. Up-regulation of collagen and tissue inhibitors of matrix metalloproteinase in colonic diverticular disease. Dis Colon Rectum 2004; 47(3):3718; discussion 378-9.

11. Simpson J, Spiller R. Colonic diverticular disease. Clin Evid 2005(14):543-50.

12. Painter NS. Diverticular disease of the colon. Br Med J 1968; 3(5616):475-9.

13. Bassotti G, Battaglia E, Spinozzi F, et al. Twenty-four hour recordings of colonic motility in patients with diverticular disease: evidence for abnormal motility and propulsive activity. Dis Colon Rectum 2001; 44(12):1814-20.

14. Brian West A. The pathology of diverticulosis: classical concepts and mucosal changes in diverticula. J Clin Gastroenterol 2006; 40(7 Suppl 3):S126-31.

15. Young-Fadok TM, Roberts PL, Spencer MP, Wolff BG. Colonic diverticular disease. Curr Probl Surg 2000; 37(7):457-514.

16. Abou-Nukta F, Bakhos C, Ikekpeazu N, Ciardiello K. Ruptured giant colonic diverticulum. Am Surg 2005; 71(12):1073-4.

17. Bahadursingh AM, Virgo KS, Kaminski DL, Longo WE. Spectrum of disease and outcome of complicated diverticular disease. Am J Surg 2003; 186(6):696-701.

18. Gollub MJ, Jhaveri S, Schwartz E, et al. CT colonography features of sigmoid diverticular disease. Clin Imaging 2005; 29(3):200-6.

19. Buckley O, Geoghegan T, O'Riordain DS, et al. Computed tomography in the imaging of colonic diverticulitis. Clin Radiol 2004; 59(11):977-83.

20. Munikrishnan V, Helmy A, Elkhider H, Omer AA. Management of acute diverticulitis in the East Anglian region: results of a United Kingdom regional survey. Dis Colon Rectum 2006; 49(9):1332-40.

21. Kirchgatterer A, Hubner D, Aschl G, et al. [Colonoscopy and sigmoidoscopy in patients aged eighty years or older]. Z Gastroenterol 2002; 40(12):951-6.

22. Nair P, Mayberry JF. Vegetarianism, dietary fibre and gastrointestinal disease. Dig Dis 1994; 12(3):177-85.

23. Aldoori WH, Giovannucci EL, Rimm EB, et al. A prospective study of alcohol, smoking, caffeine, and the risk of symptomatic diverticular disease in men. Ann Epidemiol 1995; 5(3):221-8.

24. Colecchia A, Vestito A, Pasqui F, et al. Efficacy of long term cyclic administration of the poorly absorbed antibiotic Rifaximin in symptomatic, uncomplicated colonic diverticular disease. World J Gastroenterol 2007; 13(2):264-9.
25. Tursi A, Brandimarte G, Giorgetti GM, Elisei W. Mesalazine and/or Lactobacillus casei in preventing recurrence of symptomatic uncomplicated diverticular disease of the colon: a prospective, randomized, open-label study. J Clin Gastroenterol 2006; 40(4):312-6.

26. Simpson J, Neal KR, Scholefield JH, Spiller RC. Patterns of pain in diverticular disease and the influence of acute diverticulitis. Eur J Gastroenterol Hepatol 2003; 15(9):100510.

27. Lohrmann C, Ghanem N, Pache G, et al. CT in acute perforated sigmoid diverticulitis. Eur J Radiol 2005; 56(1):78-83.

28. Parra-Blanco A. Colonic diverticular disease: pathophysiology and clinical picture. Digestion 2006; 73 Suppl 1:47-57.

29. Petrakis I, Sakellaris G, Kogerakis N, et al. New perspectives in the management of sigmoid diverticulitis. Panminerva Med 2001; 43(4):289-93.

30. Lipscomb G, Loughrey G, Thakker M, et al. A prospective study of abdominal computerized tomography and colonoscopy in the diagnosis of colonic disease in an elderly population. Eur J Gastroenterol Hepatol 1996; 8(9):887-91.

31. Parks TG. Natural history of diverticular disease of the colon. Clin Gastroenterol 1975; 4(1):53-69.

32. Roberts PL, Veidenheimer MC. Current management of diverticulitis. Adv Surg 1994; 27:189-208.

33. Stollman NH, Raskin JB. Diagnosis and management of diverticular disease of the colon in adults. Ad Hoc Practice Parameters Committee of the American College of Gastroenterology. Am J Gastroenterol 1999; 94(11):3110-21.

34. Guy RJ, Moin T. Mortality after acute surgery for complications of diverticular disease of the sigmoid colon is almost exclusively due to patient-related factors. Colorectal Dis 2006; 8(5):453.

35. Tudor RG, Farmakis N, Keighley MR. National audit of complicated diverticular disease: analysis of index cases. Br J Surg 1994; 81(5):730-2.

36. Hinchey EJ, Schaal PG, Richards GK. Treatment of perforated diverticular disease of the colon. Adv Surg 1978; 12:85-109.

37. Chandra V, Nelson H, Larson DR, Harrington JR. Impact of primary resection on the outcome of patients with perforated diverticulitis. Arch Surg 2004; 139(11):1221-4.

38. Aydin HN, Tekkis PP, Remzi FH, et al. Evaluation of the risk of a nonrestorative resection for the treatment of diverticular disease: the Cleveland Clinic diverticular disease propensity score. Dis Colon Rectum 2006; 49(5):629-39.

39. Constantinides VA, Aydin HN, Tekkis PP, et al. Long-term, health-related, quality of life comparison in patients undergoing single stage vs staged resection for complicated diverticular disease. Colorectal Dis 2006; 8(8):663-71.

40. Oomen JL, Engel AF, Cuesta MA. Outcome of elective primary surgery for diverticular disease of the sigmoid colon: a risk analysis based on the POSSUM scoring system. Colorectal Dis 2006; 8(2):91-7.

41. Oomen JL, Cuesta MA, Engel AF. Reversal of Hartmann's procedure after surgery for complications of diverticular disease of the sigmoid colon is safe and possible in most patients. Dig Surg 2005; 22(6):419-25.

42. McGuire HH, Jr. Bleeding colonic diverticula. A reappraisal of 
natural history and management. Ann Surg 1994; 220(5):653-6.

43. Zuckerman GR, Prakash C. Acute lower intestinal bleeding. Part II: etiology, therapy, and outcomes. Gastrointest Endosc 1999; 49(2):228-38.

44. Ali ZS, Al-Shaalan H, Jorgensen J. Successful treatment of massive acute lower gastrointestinal bleeding in diverticular disease of colon, with activated recombinant factor VII (NovoSeven). Blood Coagul Fibrinolysis 2006; 17(4):327-9.

45. Cohn SM, Moller BA, Zieg PM, et al. Angiography for preoperative evaluation in patients with lower gastrointestinal bleeding: are the benefits worth the risks? Arch Surg 1998; 133(1):50-5.

46. Yamaguchi T, Yoshikawa K. Enhanced CT for initial localization of active lower gastrointestinal bleeding. Abdom Imaging 2003; 28(5):634-6.

47. Gordon RL, Ahl KL, Kerlan RK, et al. Selective arterial embolization for the control of lower gastrointestinal bleeding. Am J Surg 1997; 174(1):24-8.

48. Green BT, Rockey DC, Portwood G, et al. Urgent colonoscopy for evaluation and management of acute lower gastrointestinal hemorrhage: a randomized controlled trial. Am J Gastroenterol 2005; 100(11):2395-402.

49. Najjar SF, Jamal MK, Savas JF, Miller TA. The spectrum of colovesical fistula and diagnostic paradigm. Am J Surg 2004; 188(5):617-21.

50. Carvajal Balaguera J, Camunas Segovia J, Pena Gamarra L, et al. Colovesical fistula complicating diverticular disease: onestage resection. Int Surg 2006; 91(1):17-23.

51. Grissom R, Snyder TE. Colovaginal fistula secondary to diverticular disease. Dis Colon Rectum 1991; 34(11):1043-9.
52. Walton L, Schwartz M, Photopulos G, Fowler W, Jr. Sigmoidovaginal fistulae due to diverticular disease. Two case reports and an update. Obstet Gynecol 1978; 51(1 Suppl):59s-61s.

53. Belmonte C, Klas JV, Perez JJ, et al. The Hartmann procedure. First choice or last resort in diverticular disease? Arch Surg 1996; 131(6):612-5; discussion 616-7.

54. Williams SM, Nolan DJ. Colosalpingeal fistula: a rare complication of colonic diverticular disease. Eur Radiol 1999; 9(7):1432-3.

55. Wassef R, Morgan S, Tasse D, Bernard D. [Fistulas in diverticular disease of the colon: study of 29 cases]. Can J Surg 1983; 26(6):546-9.

56. Funariu G, Bintintan V, Seicean R. Urgent surgery for complicated colonic diverticula. J Gastrointestin Liver Dis 2006; 15(1):37-40.

57. Watson AJ, Shanmugam V, Mackay I, et al. Outcomes after placement of colorectal stents. Colorectal Dis 2005; 7(1):70-3.

58. Weber WP, Guller U, Jain NB, et al. Impact of surgeon and hospital caseload on the likelihood of performing laparoscopic vs open sigmoid resection for diverticular disease: a study based on 55,949 patients. Arch Surg 2007; 142(3):253-9; discussion 259.

59. Alves A, Panis Y, Mathieu P, et al. Postoperative mortality and morbidity in French patients undergoing colorectal surgery: results of a prospective multicenter study. Arch Surg 2005; 140(3):278-83, discussion 284.

60. Senagore AJ. Laparoscopic sigmoid colectomy for diverticular disease. Surg Clin North Am 2005; 85(1):19-24, vii. 